\section{Suppressing dissent?}

SIR - The debate (F. M. Menger and A. Haim, Nature 359, 666; 1992; R. Breslow, 360, 23; 1992; R. L. Schower 360, 506; 1992) concerning the merits and refereeing of a communication to a leading periodical (Journal of the American Chemical Society or JACS) deserves, in my opinion, further brief comment.

First, it has not been explicitly recognized that communications (or letters) to leading journals (for the physical and biological sciences, Physical Review Letters, Science, Nature and JACS is a sensible if incomplete listing) are considered as a working definition of leading research in these areas and as a starting point for further studies. As such, communications (or letters) have, in addition to the usual attention and refereeing, a special obligation to be reflective, accurate and complete.

Second, of the four periodicals listed above, JACS only does not provide a forum (correspondence or comments) for an open discussion of possible errors in analysis or interpretation. Regardless of the merits of the communication in question or the subsequent correspondence, the deliberation offered in Nature should have rightfully appeared in $J A C S$; it would be sensible for that periodical immediately to take steps to provide such a medium for exchange of views.

\section{Thomas J. Kistenmacher}

Bloomberg Center

for Physics and Astronomy,

Johns Hopkins University

Baltimore, Maryland 21218, USA

SIR - Surely the time has come to institute an international code of ethics for referees? Some societies (including the American Chemical Society) have their own 'ethical guidelines', and most journals have 'instructions for authors'. But would it not be possible for editors of major scientific journals to agree to a common set of principles that would serve as general guidelines for referees, irrespective of the scientific research field?

J. F. Thackeray

Department of Palaeontology

and Palaeoenvironmental Studies, Transvaal Museum,

PO Box 413

Pretoria, South Africa

SIR - I have read with interest the article by Haim and Menger and the reply by Breslow. I am surprised by what seem to be attempts at suppressing dissent; an action that becomes neither the people involved nor their positions. In pleasant contrast is the case of Pauling
(Proc. natn. Acad. Sci. U. S. A. 86, 8595-8599; 1989) encouraging simultaneous publication of the criticism by Bancel et al. (Proc. natn. Acad. Sci. U. S. A. 86, 8600-8601; 1989) of his own work.

\section{Ram Seshadri}

Indian Institute of Science,

Bangalore 560 012, India

\section{UK research}

SIR - The numerical value of many statistical functions changes with sample class boundaries. Thus the improvement in British university research that David Dickson (Nature 360, 700; 1992) inferred from the figures released by the Universities Funding Council may be real but it may be an artefact of departmental closures, mergers and selective inclusion of staff in departmental figures. It is likely that the three-year period since the previous assessment is too short to measure any real improvement in active research, given the time-lags between grant applications and conclusion of research and between research and final publication. Much of the documented improvement could reflect a greater time spent in writing papers and grant applications with a consequent decrease in the time employed in active research. If so, the data may conceal an actual decline in the amount and quality of current research. The view that the quality of UK university science research has improved is at odds with the recently reported decline in the national science citation record. In my opinion, we currently have insufficient data to draw reliable conclusions on developments in UK science research.

\section{Jan Alexander}

Department of Geology,

University of Wales,

PO Box 914,

Cardiff CF1 3YE, UK

\section{Not in our Nature}

SIR - Several Nature issues have contained advertisements mentioning some of the important scientific discoveries orginally published in Nature, among them Darwin's theory of natural selection, the first rocket, Watson and Crick's DNA double helix, the production of monoclonal antibodies and male development of chromosomally female mice.

I understand that science is a commercial activity and that scientific journals, keystones in the edifice of science, must compete to attract readers. But scientific journals, like scientific researchers, can make mistakes, and it is the sum of all these successes and failures that determines the general course of the advance of science. As well as publicizing the most important scientific discoveries published in Nature, you should also admit to the errors you have made in rejecting important papers that went on to influence and shape their disciplines. In some cases their authors received the Nobel prize.

(1) In 1981, Nature rejected a paper by the British biochemist Robert H. Michell on signalling reaction by hormones. This paper has since been cited more than 1,800 times.

(2) In June 1937, Nature rejected Hans Krebs's letter describing the citric acid cycle. Krebs won the 1953 Nobel prize in physiology or medicine for this discovery.

(3) Nature initially rejected a paper on work for which Harmut Michel won the 1988 Nobel prize for chemistry; it has been identified by the Institute for Scientific Information as a core document and widely cited.

(4) A paper by Michael J. Berridge, rejected in 1983 by Nature, ranks at number 275 in a list of the most-cited papers of all time. It has been cited more than 1,900 times.

\section{Juan Miguel Campanario}

Grupo de Ciencia Cognitiva,

Departamento de Física,

Universidad de Alcalá,

28871 Alcalá de Henares,

Madrid, Spain

\section{Alexander Bain}

SIR - It was good to see Alexander Bain mentioned in the commemorative Commentary by J. L. Heilbron and W. F. Bynum (Nature 361, 9-12; 1993). However, his 1843 patent was of more significance than just being a description of his "premature" invention of a telegraphic fax machine. It was almost certainly the first publication proposing the important principle of scanning an image to enable it to be transmitted electrically. As such it was the precursor of many important scientific techniques as well as, of course, television technology.

Incidentally Bain died, at the age of 67 and in near penury, in 1877 not 1903 .

\section{Dennis McMullan}

Department of Physics,

University of Cambridge,

Cambridge CB3 OHE, UK

The Alexander Bain who died in 1903 was the philosopher and logician.

Various readers have pointed out Nature's error in identifying the subject of Gillray's cartoon on the cover of the 7 January 1993 issue as Lavoisier rather than Humphrey Davy.

NATURE . VOL 361 • 11 FEBRUARY 1993 